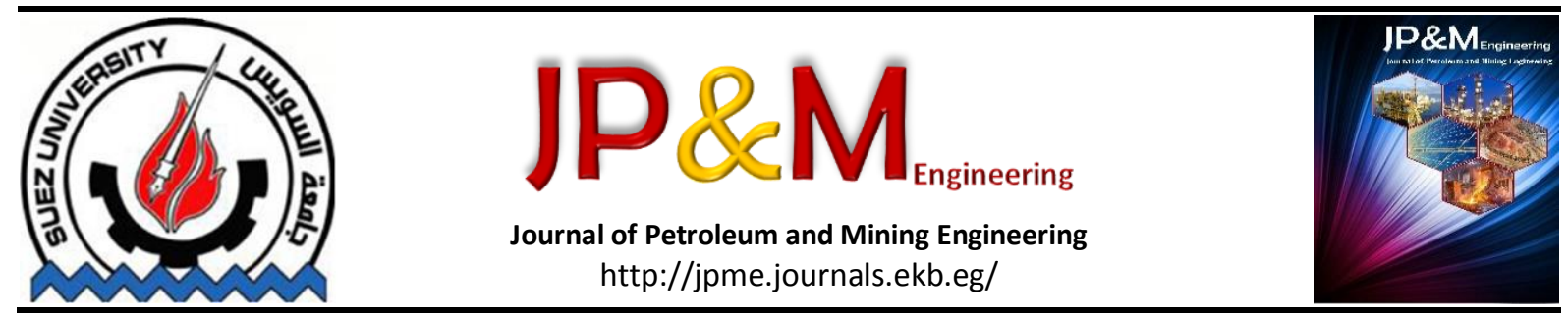

\title{
Improving the Energy Efficiency for Propane Recovery from Natural Gas using Pinch Technology: ACase Study
}

\author{
Abd-Elmawgoud, H. ${ }^{\text {a }}$, EL Temtamy, S. A. ${ }^{a}$, Gad, M. S. ${ }^{a}$, Elshiekh,T. M. ${ }^{a}$ and Aboul-Fotouh, T. M. ${ }^{b}$ \\ a Process Development Department, Egyptian Petroleum Research Institute, Nasr City, Cairo, Egypt. \\ ${ }^{\mathrm{b}}$ Mining and petroleum Engineering Department, Faculty of Engineering, Al-Azhar University, Nasr City, Cairo, Egypt \\ * Corresponding author e-mail: hussienmawgoud@yahoo.com
}

\section{Article Info}

Received 21 Oct. 2020 Revised 22 Nov. 2020 Accepted 16 Dec. 2020

\section{Keywords}

Heat integration; Energy saving; Simulation.

\begin{abstract}
Process integration (PI) techniques is an efficient approach to increase the profitability due to reduction in energy, water and raw materials consumption, reduction in greenhouse gas (GHG) emissions, and in waste generation. The PI method, pinch technology is certainly the most widely used in industrial processes. When planning a new plant or revamping an existing plant it is very important to understand and select the right process to minimize capital and operating costs. This research was directed to investigate the reduction of energy consumption in propane recovery units that process natural gas produced from wells existing in the Egyptian western desert fields. The first step was process simulation of the existing gas processing plant using Aspen HYSYS 8.3 steady state process simulation program. Next, pinch technology has been adopted in order to achieve minimum hot and cold utilities and save capital cost of the process. Target utilities were calculated using pinch analysis in the Aspen energy analyzer program. Modifications in heat exchanger network could result in savings of $8.3 \%$ in hot utility, $6.5 \%$ in cold utility of the existing plant and of $46.7 \%$ in capital cost for a grass root plant.
\end{abstract}

\section{Introduction}

One of the most important forms of energy in any industrial process is heat. In a typical process, there are many hot streams that should be cooled and vice versa. The heating and cooling utilities (e.g., steam, heating oil, cooling water and refrigerants) should be provided to accomplish the needs of process duties. The excessive use of external utilities is highly costly. Instead, integrating the process by transferring the heat from the hot streams to cold streams may lead to a significant cost reduction. This process is well known as heat exchanger networks (HENs) design. The purpose of heat integrations to utilize the existing thermal energy in a process before using external utilities. The discovery of the heat pinch in the late seventies enabled engineers to identify minimum utility targets, for the first time, ahead of design [1]. HENs design therefore, was performed in two stages. The first stage is establishing the minimum utility targets. The second stage is stream matching so as to reach these targets. There are two methods that have been used for determining the minimum utilities required in HENs. The first method is a graphical method based on the enthalpy - temperature diagram which was later developed to its mathematical equivalent known as the problem table algorithm [1].

The second method is a linear programming method based on dividing the problem into temperature intervals corresponding to streams supply and target temperatures and writing the heat balancing equations for each interval and for each stream including hot and cold utilities. LP is used to minimize the hot and cold utilities subject to the problem's constraints [2]. For the stream matching stage, also, there are two common methods the first one, the pinch design method (PDM)gives emphasis on positioning the heat exchangers by working out from the pinch temperatures while taking care of stream properties according to heuristic rules [1]. The other method uses mixed integer programming (MILP) to calculate the preferred stream matches so as to achieve minimum utilities and minimum number of exchangers [2]. Because of the difficulty of interpretation and extraction of the results especially for large scale or industrial problems, the latter method did not gain much acceptance for practical 
HENs design. On the other hand, PDM became a promising tool to optimize the energy efficiency of industrial processes [3-6]. In order to realize the maximum heat recovery and the optimal integration of utilities to supply heating and cooling requirement, a HEN has to be designed, (considering process and utility streams). One major drawback is the assumption that any hot stream can exchange heat with any cold stream. In reality, heat exchange becomes difficult or even impossible due to constraints (such as a distance between streams or quality and/or safety reasons) or due to system dynamics (such as non-simultaneous operations).

Elsewhere [7] the factors affecting propane recovery units were established and discussed on comparative basis for selecting the best process at specified conditions. A method was presented for optimizing process conditions for maximum propane recovery in a natural gas processing plant existing in the western desert of Egypt [7]. In this paper energy saving in the proposed maximum propane recovery plant was investigated. Target utilities were calculated using Aspen Energy Analyzer utility included in Aspen HYSYS simulation program. Aspen Energy Analyzer is based on the pinch technology. It calculates the scope for energy reduction, utility savings and green- house gas emissions reduction. For more details, Aspen Energy Analyzer utility can communicate with Aspen HYSYS simulation program version 3.2. Energy manger, which can then be used to understand and analyse streams' heat effects, suitably locate utilities and design maximum energy recovery networks.

\section{The Pinch Technology and Aspen Energy Analyzer}

The pinch point was discovered by constructing the temperature-enthalpy diagram of the composite curves [1]. The hot composite curve is the sum of all hot streams within the process in terms of heat load and temperature level similarly is the cold composite curve. The two curves can be represented on a single temperature-enthalpy plot [1-3] (see Fig.4). If the two curves are moved towards each other, they touch at the pinch point. It is apparent that heat can be recovered within the process; there is a portion of hot curve above the cold curve where, according to the second law of thermodynamics, heat can flow from the higher temperature part of the process to the lower part. To keep the size of the heat recovery equipment reasonable, the temperature difference (approach) must be large enough or equal to a defined minimum allowable temperature approach, $\Delta \mathrm{T}_{\min }$.

Minimum hot and cold utilities are the overshoots of the cold and hot composites at the highest and lowest temperatures respectively. Based on the pinch point discovery and the quantification of the target utilities, a full complete methodology for a systematic design of HENs that achieve target utilities has emerged, known as the pinch design method [8]. Aspen Energy Analyzer utilizes this technology; it extracts the hot and cold process streams from a previously simulated process flow diagram and calculates the prospects of savings in utilities and capital costs and reduction of greenhouse gases as a result of saving in energy. It draws the composite curves, locates the pinch point and draws the grid diagram. The user then chooses the hot and cold utilities and decides, step by step his/her choices for stream matching. Aspen Energy Analyzer then calculates the required area, number of shells and cost for each heat exchanger as well as for the entire HEN.

\section{Design Approach and Process Description}

The design approach aimed to analyse and improve the performance of the proposed propane production process with respect to energy. Energy saving potential was investigated using Aspen Energy Analyzer utility after steady state simulation of the proposed maximum propane recovery process using of Aspen HYSYS software. Accordingly, a new HEN was designed, and the results were analysed using Aspen Energy Analyzer.

\section{Process Description of the Proposed Maximum Propane Recovery Gas Plant}

This is a case of a natural gas processing plant that exists in Egyptian western desert which processes $153056.5 \mathrm{Kg} / \mathrm{h}$ of natural gas produced from western desert gas fields. Typical analysis of the feed natural gas is shown in Table1. The plant comprises the following main process; inlet receiving unit; condensate stabilization; primary refrigeration units; dehydration unit (adsorption unit); secondary refrigeration (plate heat exchanger and turbo expander) and fractionation units.

Table 1 Natural gas feed stream analysis.

\begin{tabular}{|c|c|}
\hline Component & Mole fraction \\
\hline Methane & 0.8175 \\
\hline Ethane & 0.0704 \\
\hline Propane & 0.0259 \\
\hline i-Butane & 0.0080 \\
\hline n-Butane & 0.0064 \\
\hline i-Pentane & 0.0037 \\
\hline n-Pentane & 0.0022 \\
\hline n-Hexane & 0.0036 \\
\hline n-Heptane & 0.0040 \\
\hline n-Octane & 0.0039 \\
\hline n-Nonane & 0.0020 \\
\hline n-Decane & 0.0033 \\
\hline CO2 & 0.0030 \\
\hline Nitrogen & 0.0004 \\
\hline H2O & 0.0456 \\
\hline
\end{tabular}

A model of the steady state gas processing plant has been built using Aspen HYSYS simulation program version 3.2., in order to simulate the operating condition as well as all equipment included in the plant. The flow sheet simulation of the optimized propane recovery production plant is shown in Figure1. The natural gas feed (stream1) enters the three-phase separator $\mathrm{V}-100$ at a pressure 53.9 bar-g and temperature $38^{\circ} \mathrm{C}$ where water (wa3) and liquid hydrocarbon (condensate) are separated from the gas 
stream (stream 3). The Condensate (stream 2) is directed through a Joule Thomson valve VLV-100 to reduce the pressure to $7.6 \mathrm{bar}-\mathrm{g}$ and temperature to $30.4^{\circ} \mathrm{C}$, then (stream 20) flows to the two-phase separator V-102 where gases are separated from the condensate(stream21) which enters the stabilization column T-103.

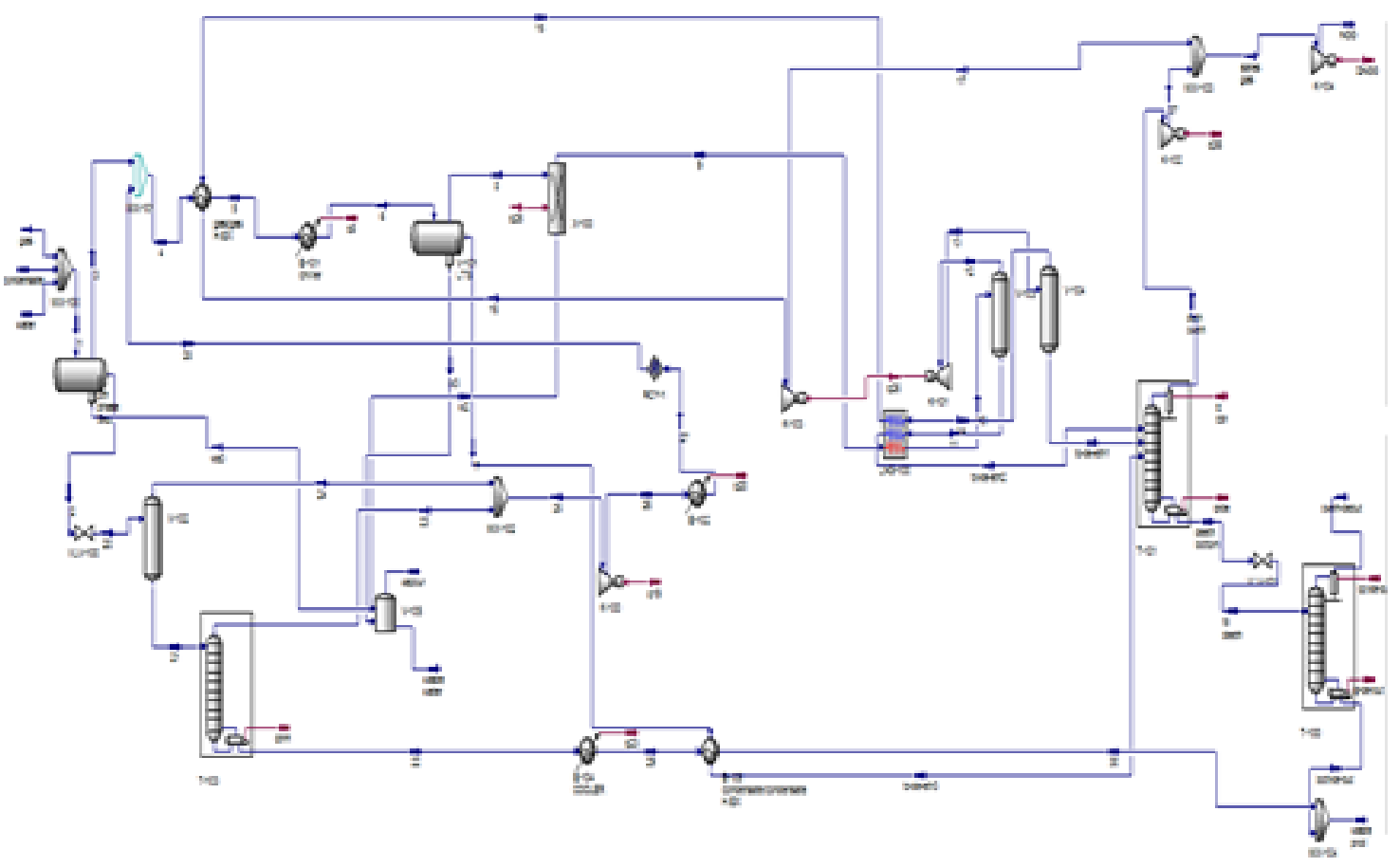

Figure 1 Simulation of the original flow diagram of the propane production process

The extracted gas from the top of the column (stream 23) is mixed with the separated gas from two phase separator (stream 24) and are compressed from 5.8 bar-g and $38^{\circ} \mathrm{C}$ to $52.3 \mathrm{bar}-\mathrm{g}$ and $180^{\circ} \mathrm{C}$, then (stream 26) is directed to cooler E-102 to be cooled to $450 \mathrm{C}$. Stream 28ismixed with the gas stream (stream 3 ) exiting the top of the separator to form stream 4. The condensate (stream 7) from LTS (low temperature separator) flows to condensate/condensate heat exchanger E-105 to cool the condensate (stream 22) from stabilization column $\mathrm{T}-103$ from temperature 530 to $45^{\circ} \mathrm{C}$ and then is mixed with heavy hydrocarbon from de-propanizer column T-102 as condensate product. Stream 4 is passed to the gas/gas heat exchanger E-101, where the mixed gases (stream 4) are cooled by stream 15 to $3.8^{\circ} \mathrm{C}$ and the outlet gas (stream 5 ) is cooled further by propane refrigeration in cooler E-103 to $-9.5^{\circ} \mathrm{C}$. The cooled gas (stream 6) flows to low temperature separator LTS V-101 to separate all remained free water and condensate from the gas stream.

The gas from LTS (stream 8) is directed to the adsorption tower (component splitter in Aspen-Hysys simulation) X-100 to separate all water vapor in the gas stream. The dehydrated gas (stream 9) entered the plate heat exchanger NG-100 where it is cooled to$35.50 \mathrm{C}$ by two streams 14,11 from the two separators $\mathrm{V}-103$ and $\mathrm{V}-104$ respectively. The exit stream from NG-100 (stream 10) is directed to the two-phase separator V-103 to separate condensate (stream11) that was used for cooling stream 9 in NG-100 and the gas (stream 12) is expanded in turbo expander K-101 to reduce its pressure from $50.8 \mathrm{bar}-\mathrm{g}$ to $37.4 \mathrm{barg}$ and temperature from $-35.5^{\circ} \mathrm{C}$ to $-49.1^{\circ} \mathrm{C}$.
The stream from turbo-expander (stream 13) enters the two-phase separator V-104 to separate light gases (stream 14) from the condensed liquid. The liquid condensate from V-104 (stream to-de-eth3) entered de-ethanizer column T-101. The de-ethanizer column operated at pressure 27.6bar-g and temperature- $72.8^{\circ} \mathrm{C}$ at the top of the column and 27.9 bar-g, $105.5^{\circ} \mathrm{C}$ at bottom of the column with 28 trays. The outlet gases from the top of the de-ethanizer column stream (de-ethanizer-overhead) are compressed to 33. 9bar-g and are further compressed to68.9 bar-g (stream natural gas).

The heavy hydrocarbon from the bottom of the de-ethanizer column (Stream de-ethanizer bottom) passed through Joule-Thomason valve VLV-101 to reduce pressure to $12.2 \mathrm{bar}-\mathrm{g}$ and temperature to $70.60 \mathrm{C}$ (stream to-de-prop) then flowed to depropanizer column T-102. C2+ hydrocarbon liquids from de-ethanizer unit entered tray \# 10 of the depropanizer column at $70.6^{\circ} \mathrm{C}$ and $12.2 \mathrm{bar}-\mathrm{g}$. As the liquid moved down through the valve trays C3 hydrocarbons were stripped off. The liquid from the bottom of the column entered the reboiler where stripping stream was generated at the temperature of $118{ }^{\circ} \mathrm{C}$ which rose up in the tower. The stripped C3vapors exited the column from the top and entered the condenser. Part of the liquid propane from the condenser entered top tray of the column as reflux, and propane product was directed to storage.

\section{Energy Targeting}

At this step, energy targeting was performed to benchmark the performance of the process [9]. The necessary data: the supply and target temperatures of the hot and cold process streams as well as the 
utilities were extracted from flow sheet simulationFigure1.

Table 2 displays the extracted process streams temperatures as well as their thermal properties. A preliminary investigation for the scope of energy saving was conducted using Aspen Hysys simulation program, at an experience value for minimum approach temperature of $10^{\circ} \mathrm{C}$. The results shown in
Table3, revealed that there was a prospect for savings in both hot and cold utilities of $12 \%$ and $4 \%$ respectively and an equivalent reduction of greenhouse gases as a result of savings in both utilities. Detailed thermal pinch analysis was then conducted using Aspen Hysys simulation program by pressing the button for details on Aspen Energy Analyzer utility toolbar.

Table 2 Stream data for the purpose production plant

\begin{tabular}{|c|c|c|c|c|}
\hline Stream & $\mathrm{T}_{\text {in }}{ }^{\circ} \mathrm{C}$ & $\mathrm{T}_{\text {out }}{ }^{\circ} \mathrm{C}$ & Enthalpy difference $\mathrm{kJ} / \mathrm{h}$ & $\begin{array}{c}\text { Flowrate } \\
\text { kg/h }\end{array}$ \\
\hline Stream26to Stream28 & 180.1 & 45 & 853122.6 & 2242.44 \\
\hline from E102to Stream18 & 5.8 & 34.6 & 2076161 & 29870.8 \\
\hline Dethanizer overhead to Stream16 & -72.84 & 13.2 & 28180678 & 130524.4 \\
\hline Stream 22to waste product & 170.5 & 55 & 4192842 & 14054.2 \\
\hline Stream 9 to Stream 10 & -8.1 & -35 & 13803159 & 144624.9 \\
\hline Stream4 to Stream6 & 37.7 & -8 & 20505235 & 153056.5 \\
\hline $\begin{array}{l}\text { From condenser@COL1 } \\
\text { to_dethanizer overhead@COL1 }\end{array}$ & -61.8 & -72.8 & 18217931 & 159825.5 \\
\hline From reboiler@COL3 to H.EX@COL3 & 131.4 & 170.5 & 5302838 & 24522.2 \\
\hline condenser@COL2 & 46.8 & 46.5 & 8817489 & 39638.3 \\
\hline reboiler@COL1 & 93.75 & 105.5 & 19572109 & 106765.6 \\
\hline reboiler@COL2 & 106.35 & 118.1 & 10196274 & 49555.2 \\
\hline
\end{tabular}

Table 3 Potential for Energy and green house reduction in the gas plant.

\begin{tabular}{|l|c|c|c|c|c|c|c|}
\hline \multirow{2}{*}{ Utility } & \multicolumn{3}{|c|}{ Energy (kJ/h) } & \multicolumn{2}{c|}{ Green house gases (kg/h) } & saving \\
\cline { 2 - 8 } & Current & Target & Saving potential & Current & Target & $\begin{array}{c}\text { Saving } \\
\text { potential }\end{array}$ & $\%$ \\
\hline HP Steam & $5.30 \mathrm{E}+06$ & $7.71 \mathrm{E}+05$ & $4.53 \mathrm{E}+06$ & 296.4 & 43.1 & 253.3 & 85 \\
\hline MP Steam & $1.09 \mathrm{E}+07$ & $4.29 \mathrm{E}+06$ & $5.90 \mathrm{E}+06$ & 569.9 & 239.9 & 329.9 & 58 \\
\hline LP Steam & & & & & & & \\
\hline Total Hot Utilities & $1.98 \mathrm{E}+07$ & $2.78 \mathrm{E}+07$ & $-8.2 \mathrm{E}+06$ & 1094 & 1553 & -459.1 & -42 \\
\hline Refrigerant 4 & $3.51 \mathrm{E}+07$ & $3.29 \mathrm{E}+07$ & $2.22 \mathrm{E}+06$ & 1960 & 1836 & 124.1 & 12 \\
\hline Air & $1.82 \mathrm{E}+07$ & $1.78 \mathrm{E}+07$ & $3.83 \mathrm{E}+05$ & 1018 & 996.8 & 21.4 & 2 \\
\hline Refrigerant 1 & $8.82 \mathrm{E}+06$ & $8.18 \mathrm{E}+06$ & $6.42 \mathrm{E}+05$ & 492.8 & 456.9 & 35.9 & 7 \\
\hline Total Cold Utilities & $8.41 \mathrm{E}+06$ & $7.22 \mathrm{E}+06$ & $1.20 \mathrm{E}+06$ & 470.2 & 403.4 & 66.8 & 14 \\
\hline
\end{tabular}


Targeting for Minimum Annualized Cost. Choosing the Minimum Approach Temperature.

It is known that the choice of the minimum approach temperatures is a crucial factor in determining the total annual cost of HENs; as the temperature approach increases the utility cost increases and the capital cost decreases, and the reverse is true. Ahmed and Linnhoff [10] introduced the super targeting concept, i.e. choosing the optimum $\Delta T_{\min }$ that realizes the least annual cost ahead of design. Aspen HYSYS simulation program, energy manger has the facility to calculate both capital and operating costs, as well as total annualized cost for a given $\Delta T_{\min }$ range. Figure 2 shows $\Delta T_{\text {min }}$ as the $X$ axis versus operating cost and capital cost as the $Y$-axis. WhileFigure 3 showed the same $X$ axis but with the total annualized cost as the $Y$ axis. Minimum annualized costs shown to lay between $5-10^{\circ} \mathrm{C}$ for $\Delta \mathrm{T}_{\min }$. It was decided to choose $8^{\circ} \mathrm{C}$ as $\Delta \mathrm{T}_{\min }$.

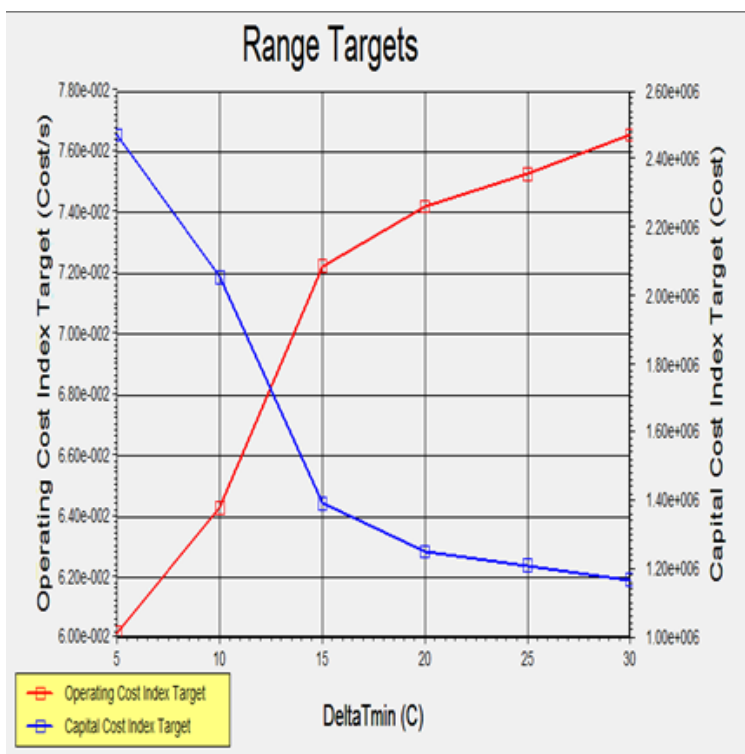

Figure $\mathbf{2} \Delta \mathrm{T}_{\min }$ versus operating cost and capital cost.

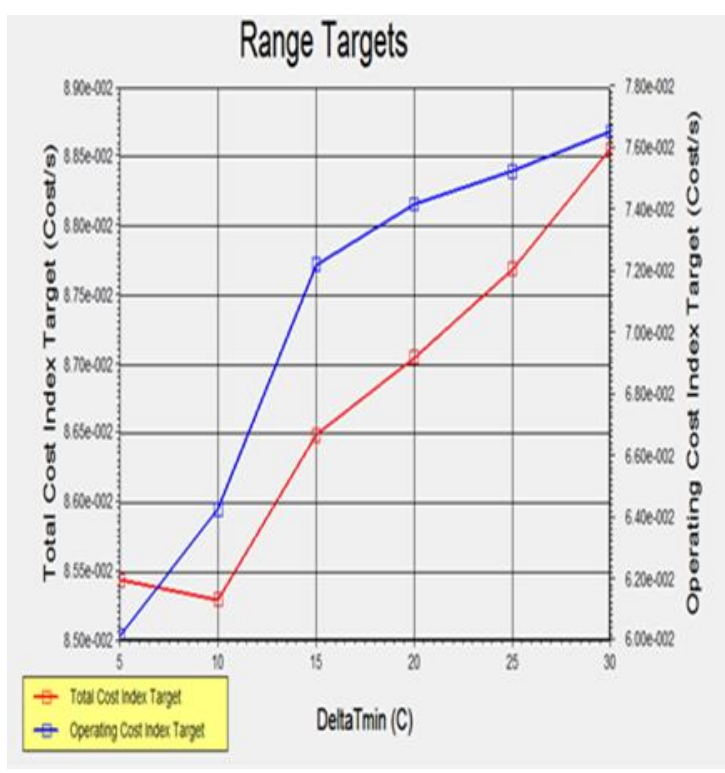

Figure $3 \Delta T_{\min }$ versus the total annualized cost.
Energy targeting at $\Delta \mathrm{T}_{\min }=8^{\circ} \mathrm{C}$ was conducted using HYSYS simulation program, energy analyzer program and was represented on composite curve as illustrated in Figure4.The results of energy targetingwere $3.2 \times 10^{7} \mathrm{~kJ} / \mathrm{h}$ for the minimum hot utility and $3.3 \times 10^{7} \mathrm{~kJ} / \mathrm{h}$ for the minimum cold utility with the thermal pinch point at temperature $101.7^{\circ} \mathrm{C}$ for the hot composite curve and $93.7^{\circ} \mathrm{Cfor}$ the cold composite.

\section{Utility Targeting.}

There are many types of utilities available on the plant site. These are namely, high pressure steam, medium pressure steam and low-pressure steam as hot utility and refrigerants 1,2 , 3and 4 in addition to water and air as cold utilities. Utility targeting can best be determined using the grand composite curve Figure5. Suitable utilities are shown as the horizontal lines stretching from the vertical temperature axis on the left to meet the GCC with their duties as read on the horizontal enthalpy axis. The chosen utilities are high pressure steam, medium pressure and lowpressure steam for the hot utilities and air, refrigerant 1 and refrigerant 4 for the cold utilities. Table 4 shows Aspen Energy analyzer calculations for the utility targets.

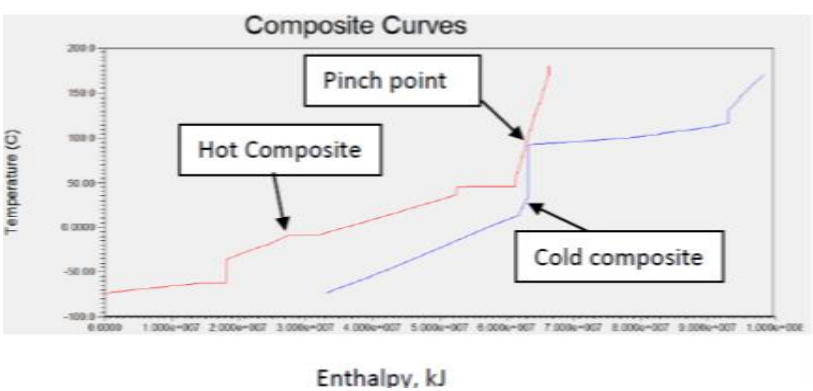

Figure 4 Composite Curves

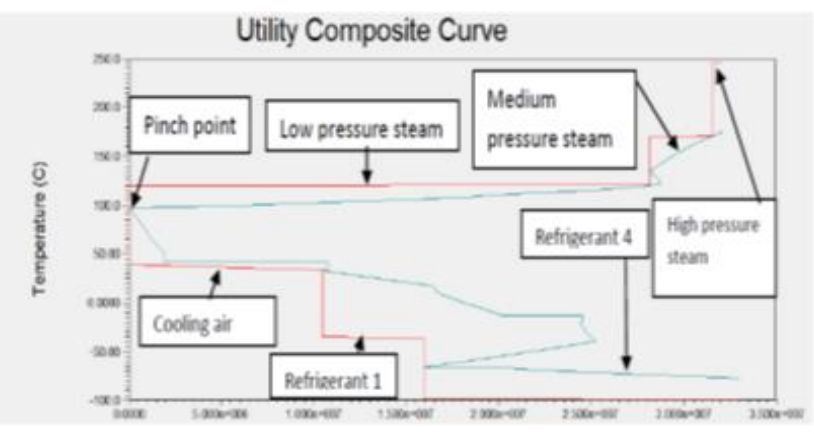

Enthalpy, $\mathbf{E}$

Figure 5 Grand composite curve showing placement of the different utilities.

\section{Heat Exchanger Network Retrofitting}

Here we apply the retrofit mode of Aspen Energy analyzer. It constructs the grid diagram where hot streams/hot utilities extend from the left to the right while cold streams/cold utilities extend from the right to the left. We were free to match any hot stream with any cold stream keeping in mind that the resulting HEN is as close as possible to the existing one and the approach temperature at each side of the proposed heat exchanger does not fall below the specified $\Delta T \min$. 
Trying to apply the pinch rules $[3,8]$, starting from the hot side of the pinch, we find that there were two hot streams entering the pinch but there is only one cold stream which had to be split into two branches.

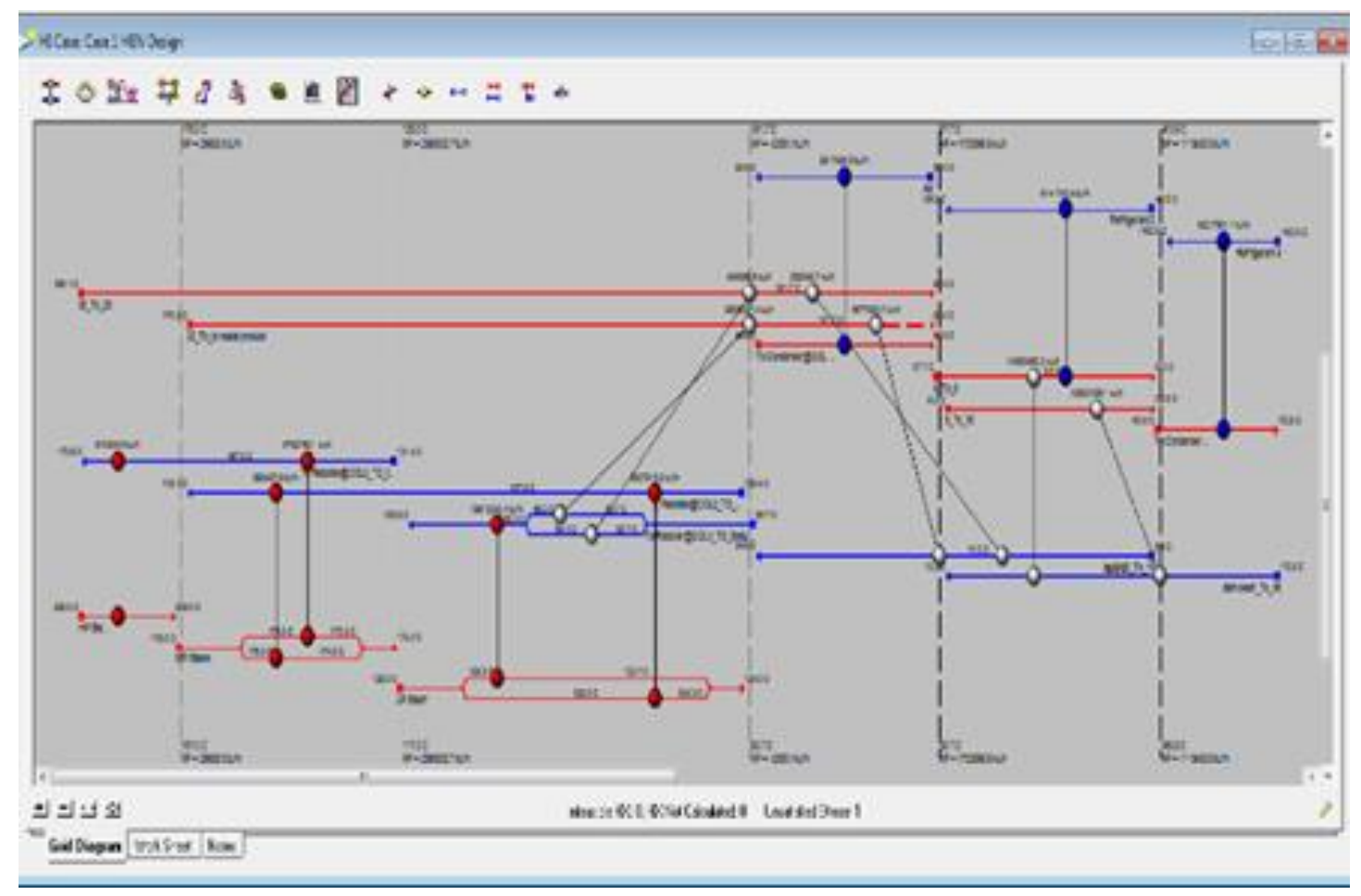

Figure 6 The grid diagram for case 1 with one split of a cold stream above the process pinch.

Considering the cold side of the pinch there are no cold streams reaching the pinch, i.e., no pinch matches are required; therefore, we are free to match any hot stream with any hot stream [9-12]. Figure6. shows the grid diagram with five pinches; only one pinch $\left(101.7-93^{\circ} \mathrm{C}\right)$ is the process pinch, others are utility pinches. The resulting design (case 1 ) is shown in Figure 6. In this design only one stream is not satisfied i.e., it does not reach the target temperature, but this is a waste stream, and its target temperature is not a firm temperature.

Stream splitting complicates the design and control of HEN. In an alternative design and to fulfil pinch design technology requirement that no clod utility should be used above the pinch, we relaxed the heuristic of equal number of pinch matches for both hot and cold streams. Also heat crossing the pinch was allowed for the sake of simplicity. The alternative HEN design (case 2) is shown in Figure7. Fortunately, the two designs are almost satisfying target requirements for both hot and cold utilities. Nevertheless, Table 4 shows that for each type of utility, individual targets were not strictly satisfied, otherwise, we should have used more utility exchangers for the same stream i.e., we sacrificed operating cost for capital cost.

Performance evaluation for each HEN is displayed in Table 5. Also shows that the number of heat exchangers, the number of shells and the capital cost are much lower in the designed networks as compared to the targeted values. On the other hand, operating cost is only $4.8 \%$ higher than the target value.

The Main Changes from The Original HEN.
The existing plate heat exchanger NG-100 to be replaced with shell and tube heat exchanger E-104 to save utility, capital and operation cost (in case of making a grass root design). In order to make use of the low temperature of the de-ethanizer overhead stream (sales gas) it is first used to cool stream 25 through a process heat exchanger E100 thus eliminating the original water cooler, then it is used to cool stream 22 (stabilizer bottoms) through the heat exchanger E102 thus replacing air cooler E-104 and heat exchanger E-105.

Three new small area process heat exchangers (E106, E-107 and E-108), to be added for exchanging part of the heat in hot streams $(22,26)$ with column reboiler feeding streams (stabilizer column, deethanizer column and de-propanizer column) to save the hot utility loads.

\section{Energy Saving Results}

In this step the energy that resulted from the previous steps were evaluated by comparing it with the energy before heat integration $[5,11]$.

Target for percentage saving in utility=

$\left(\frac{\text { Utility before integration-utility after integration }}{\text { Utility before integration }}\right) \times 100$

$$
\frac{\left(3.549 * 10^{10} * 3.317 * 10^{10}\right) * 100}{3.549 * 10^{10}}=6.5 \%
$$


Table 4 Aspen Energy analyser calculations of individual utilities for HENL

\begin{tabular}{|l|r|r|r|l|r|l|l|}
\hline $\begin{array}{l}\text { Utility } \\
\text { heating }\end{array}$ & $\begin{array}{l}\text { Cost Index } \\
\text { Cost/s }\end{array}$ & Load kJ/h & $\begin{array}{l}\text { \% of } \\
\text { Target }\end{array}$ & cooling utility & Cost Index Cost/s & LoadkJ/h & $\%$ of Target \\
\hline $\begin{array}{l}\text { LP } \\
\text { Steam }\end{array}$ & $1.37 \mathrm{E}-02$ & 26049860 & 92.6 & Refrigerant 4 & $4.32 \mathrm{E}-02$ & 18217931 & 106.5 \\
\hline $\begin{array}{l}\text { HP } \\
\text { Steam }\end{array}$ & $3.54 \mathrm{E}-04$ & 510304.9 & 106.4 & Refrigerant 1 & $5.74 \mathrm{E}-03$ & 6141742 & 111.4 \\
\hline $\begin{array}{l}\text { MP } \\
\text { Steam }\end{array}$ & $3.33 \mathrm{E}-03$ & 5451250 & 160.7 & Air & $2.45 \mathrm{E}-06$ & 8817489 & 84.4 \\
\hline Total & $1.74 \mathrm{E}-02$ & 32011414 & 100 & Total & $4.89 \mathrm{E}-02$ & 33177162 & 100.3 \\
\hline
\end{tabular}

Table 5. Network Performance evaluation for each HEN

\begin{tabular}{|c|c|c|c|c|l|}
\hline \multirow{2}{*}{ Item } & \multirow{2}{*}{ Target } & \multicolumn{2}{|c|}{ HEN 1 } & \multicolumn{2}{c|}{ HEN2 } \\
\cline { 3 - 6 } & & HEN & \% of Target & HEN & \% of Target \\
\hline Heating Ld. kJ/h & 32009589 & 32011414 & 100 & 32101302 & 100.3 \\
\hline Cooling Ld. kJ/h & 33071307 & 33177162 & 100.3 & 33177162 & 100.3 \\
\hline number of units & 16 & 14 & 63.6 & 13 & 76.5 \\
\hline Number of shells & 93 & 23 & 24.7 & 22 & 23.66 \\
\hline Total Area,1-2 shell \&tube & 5578.786 & 5300.063 & 95 & 4836.525 & 86.7 \\
\hline Heating [cost/s] & $1.72 \mathrm{E}-02$ & $1.74 \mathrm{E}-02$ & 101 & $1.73 \mathrm{E}-02$ & 100.6 \\
\hline Cooling [cost/s] & $4.56 \mathrm{E}-02$ & $4.89 \mathrm{E}-02$ & 107 & $4.88 \mathrm{E}-02$ & 107 \\
\hline Operating cost [cost/s] & $6.30 \mathrm{E}-02$ & $6.63 \mathrm{E}-02$ & 105 & $6.60 \mathrm{E}-2$ & 104.8 \\
\hline Capital cost & 2151360 & 1443266 & 67 & 1342000 & 62.4 \\
\hline Annualized total cost[cost/s] & $8.49 \mathrm{E}-02$ & $8.11 \mathrm{E}-02$ & 95 & $8.31 \mathrm{E}-02$ & 97.9 \\
\hline
\end{tabular}

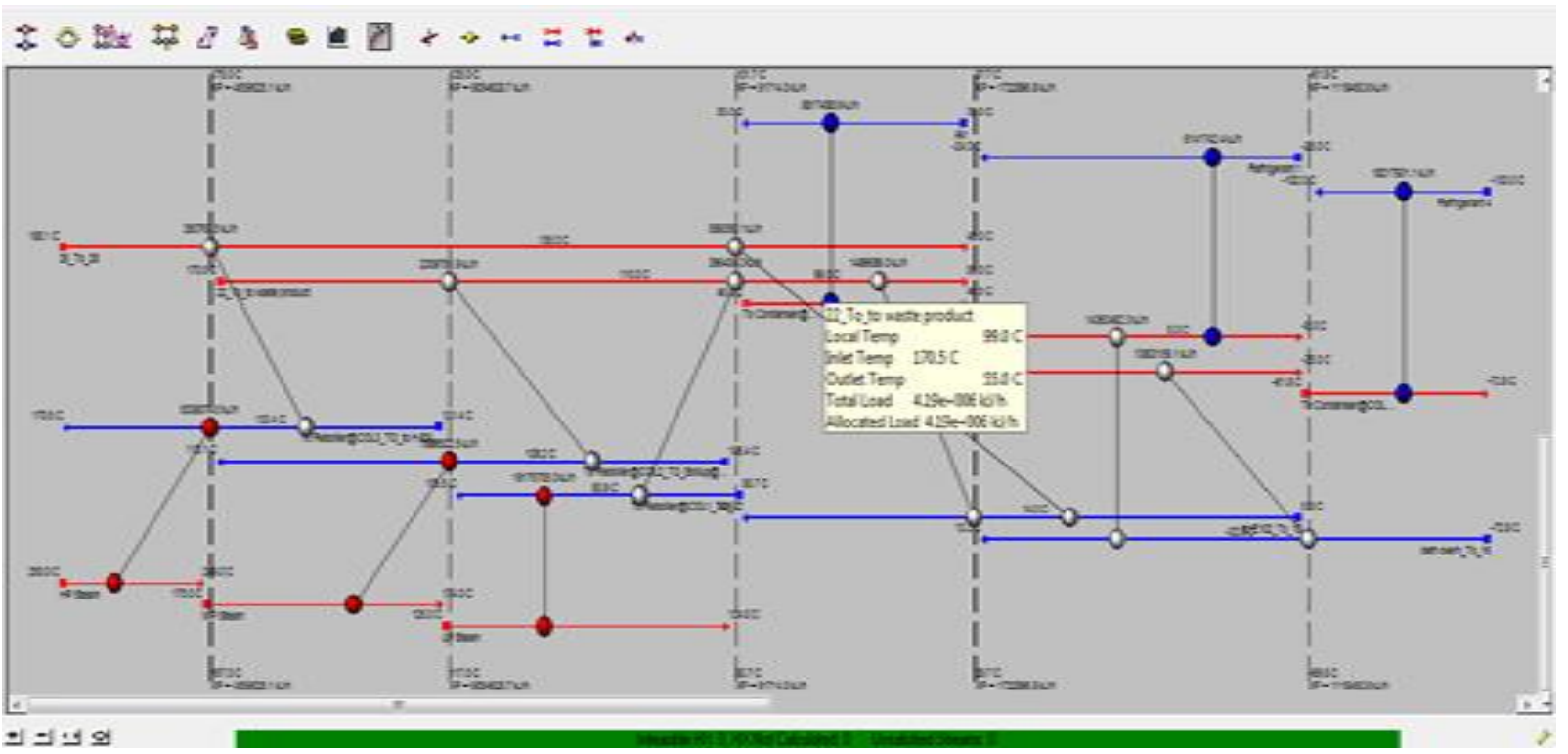

Figure 7 The grid diagram for case 2 with no split of a cold stream above the process pinch. 


\section{Conclusions}

This paper investigates energy reduction in propane production plantas a case study in an Egyptian natural gas processing plantusing of the Aspen Energy Analyzer utility in Aspen Hysys program software. Hot utility could be reduced from $3.507^{\times}\{10\}^{\wedge}\{10\} \mathrm{J} / \mathrm{h}$ to $3.216^{*}\{10\}^{\wedge}\{10\} \mathrm{J} / \mathrm{h}$ with percentage saving equals 8.3 $\%$. The same $8.3 \%$ could be saved in greenhouse gas emissions. Coldutility could be reduced from $3.549^{\star}\{10\}^{\wedge}\{10\} \mathrm{J} / \mathrm{h}$ to $3.317^{\star}\{10\}^{\wedge}\{10\} \mathrm{J} / \mathrm{h}$ with percentage savings equals $6.5 \%$. For a grass root plant, the proposed design could save the capital cost of heat exchanger networks from 2,376,561.4 \$ for the original design to $1,266,889.5 \$$ with percentage saving equals $46.7 \%$.

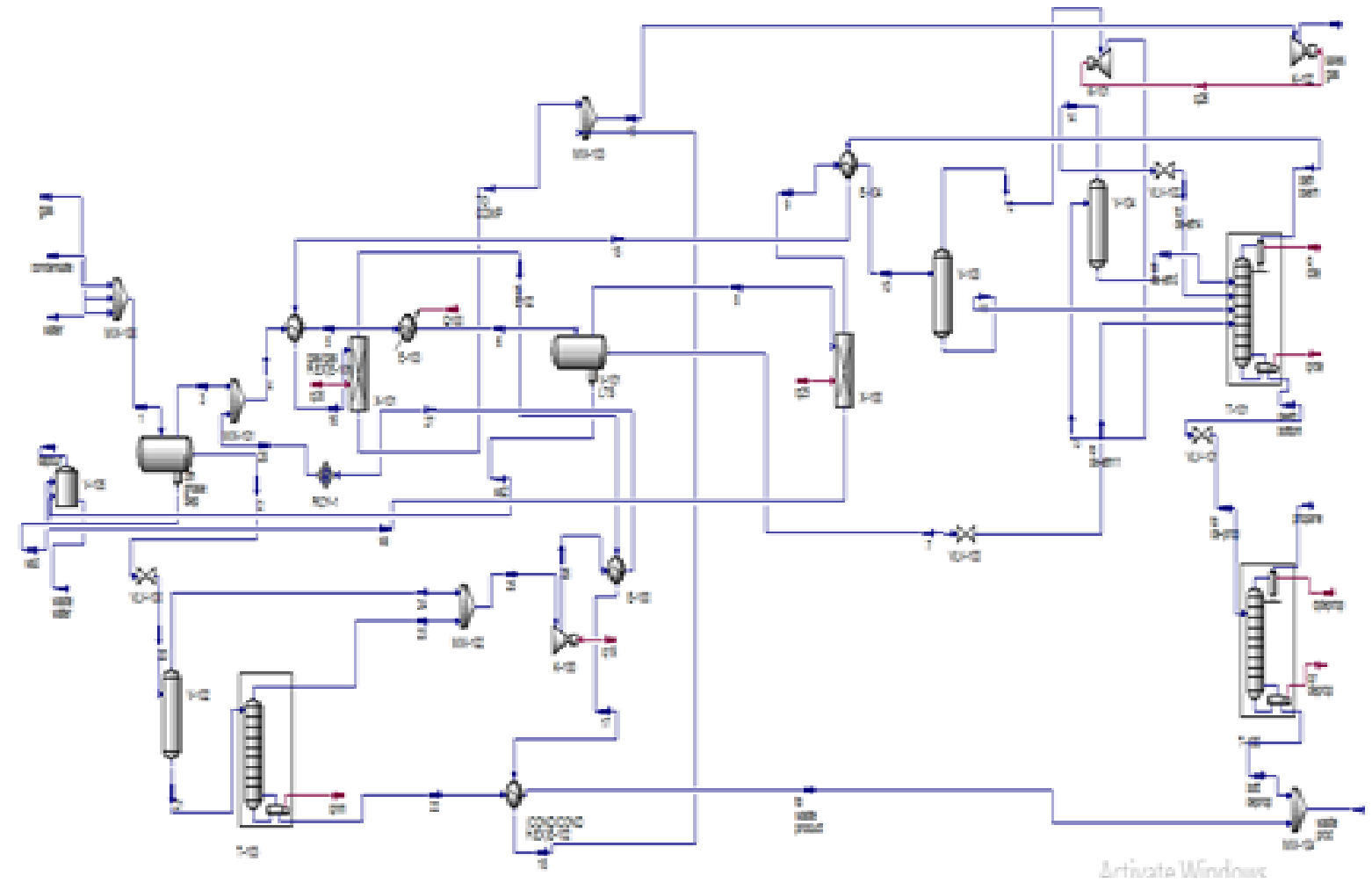

Figure 8 Flowsheet simulation of the energy optimized propane recovery production plant.

\section{Funding sources}

This research received no external funding.

\section{Conflicts of interest}

There are no conflicts to declare.

\section{References}

[1] B. Linnhoff and J. R. Flower, Synthesis of heat exchanger networks: I. systematic generation of energy optimal networks, AIChE Journal., 24 (17), (1978) 633-642.

[2] S. Papoulias, I. A. Grossmann Structural optimization approach in process synthesis-II: heat recovery networks. Computers and Chemical Engineering, 7(6), (1983)707-721.

[3] B. Linnhoff, E. Hindmarsh, The pinch design method for heat exchanger network. Chemical Engineering Science, 38 (5) (1983)745-763.

[4] Alan P. Rossiter, Improve energy efficiency via heat integration, American institute of Chemical Engineers. AIChE (2010).

[5] O. Koku, S. Perry, J-K Kim, Techno-economic evaluation for the heat integration of vaporization cold energy in natural gas processing, Applied Energy. 114, (2014)250-261.

[6] S. Al-Sobhi, H. Alfadala, M. El-Halwagi, Simulation and Energy Integration of a Liquefied Natural Gas (LNG) Plant, Proceedings of the 1stAnnual Gas Processing Symposium H. Alfadala, G.V. Rex Reklaitis and M.M. ElHalwagi (Editors) (C) 2009.

[7] Elsevier B.V. All rights reserved. Available from: https://www.

Researchgate.net/publication/267692653_Simulation_ and_Energy_Integration_of_a_Liquefied_Natural_Gas _LNG_Plant [accessed May 21, 2019].

[8] Mohamed S Gad. Optimizing the propane recovery from western desert gas fields, Ph. D. Thesis, Al-Azhar University. pp 66-78, (2016).

[9] B. Linnhoff, D. W. Townsend, D. Boland, G. F. Hewitt, B. E. A. Thomas, A. R. Guy, and R. H. Marsland, A User 
Guide on Process Integration for the Efficient Use of Energy. Oxford: Pergamon Press (1982).

[10] M. Bagajewicz, G. Valtinson, and D. N. Thanh, Retrofit of Crude Units pre Heating Trains: Mathematical Programming vs. Pinch Technology, Ind. Eng. Chem. Res.52 (42), (2013)14913-14926.

[11] S. Ahmad, B. Linnhoff, and R. Smith, Cost optimum heat exchanger network 2. Comput. Chem. Eng. 7 (1990)751-767.

[12] S. A. El-Temtamy, I. Hamid, E. M. Gabr, and A. E. R. Sayed, The Use of Pinch Technology to Reduce Utility Consumption in a Natural Gas Processing Plant Petroleum Science and Technology, 28 (2010) 13161330. 